\title{
A rotatividade de enfermeiros e médicos: um impasse na implementação da Estratégia de Saúde da Família
}

\author{
Nurses and doctors turnover: \\ an impasse in the implementation of the Family H ealth Strategy
}

\author{
Cássia Regina Gotler M edeiros ${ }^{1}$ \\ Álvaro Gustavo Wagner Junqueira ${ }^{2}$ \\ Glademir Schwingel ${ }^{1}$ \\ Ioná Carreno ${ }^{1}$ \\ Lúcia Adriana Pereira J ungles ${ }^{1}$ \\ Olinda M aria de Fátima Lechmann Saldanha ${ }^{1}$
}

\footnotetext{
${ }^{1}$ Centro Universitário Univates. Rua Avelino Tallini 171, Universitário. 95900-000 Lajeado RS. cassiargm@terra.com.br ${ }^{2} 16$ a Coordenadoria Regional deSaúde, Secretaria Estadual deSaúde (RS).
}

Abstract The research analyzed the causes for turnover rate of doctorsand nurses in family health strategy teams with at least two years of implementation on March 2006 in Vale do Taquari, Rio Grande do Sul State. It is a quantitative and qualitativestudy identifying 31 teams in 25 towns, and theturnover ratewas established by year from 1999 to 2005 by professional category. There was no turnover for doctors and nurses in 1999 and 2000. Doctor turnover was $5.9 \%$ in $2002 ; 32.1 \%$ in 2003; $25.8 \%$ in 2004; and $64.5 \%$ in 2005. Regardingnurses, it was $27.7 \%$ in 2001; $47 \%$ in 2002; $17.8 \%$ in $2003 ; 41.9 \%$ in 2004 ; and $22.6 \%$ in 2005 . The analysis of semi-structured interviews with 7 doctors and 7 nurses appointed as main causes for turnover: poor work links, fragmented education, authoritarian way of managing, no links with the community, and poor work conditions. Thus, it is necessary to make changes regarding labor links, work conditions, and education for health workers and managers, seeking for the integrality in health practices.

Key words Family H ealth Program, Health managing, Public health policies
Resumo A presente pesquisa analisou as causas do índice de rotatividade de médicos e enfermeiros das equi pes da Estratégia deSaúdeda Família, com no mínimo dois anos de implantação em março de 2006, no Vale do Taquari (RS). É um estudo quanti-qualitativo queidentificou 31 equipes em 25 municípios, sendo o índice de rotatividade estabelecido por ano, de 1999 até2005, e por categoria profissional. Em 1999 e 2000, não houverotatividade demédicoseenfermeiros. Em 2002, a rotatividade de médicos foi de 5,9\%; em 2003, de $32,1 \%$; em 2004, de $25,8 \%$ e, em 2005, de $64,5 \%$. Q uanto aos enfermeiros, em 2001, a rotatividade foi de $27,3 \%$; em 2002, de $47 \%$; em 2003, de $17,8 \%$; em 2004, de 41,9\% e, em 2005, de 22,6\%. A análise de conteúdo das entrevistas semiestruturadas realizadas com sete médicos e sete enfermeiros apontou como principais causas de rotatividade a precarização do vínculo detrabal ho, a fragmentação da formação, o estilo de gestão autoritário, a ausência de vínculo com a comunidade e más condições de trabalho. Esse contexto revela a necessidade dedesen cadear mudanças em relação aos vínculos trabalhistas, às condições de trabal ho eà formação de trabalhadores e gestores da saúde, buscando a implementação da integralidade nas práticas de saúde.

Palavras-chave Saúde da família, Gestão em saúde, Políticas públicas de saúde 
Introdução

O Programa de Saúde da Família (PSF) foi apresentado em 1994 pelo Ministério da Saúde, na busca de ações de promoção e proteção à saúde do indivíduo, da família e da comunidade, por meio de equipes quefarão o atendimento naunidade local de saúde e na comunidade ${ }^{1}$.

Segundo Franco e M erhy², à equipe, seinscreve uma determinada população do território, articulando assim a idéia de vínculo que tem como princípio a constituição de referências do usuário para com os profissionais que deverão se responsabilizar para o cuidado à sua clientela.

A partir de 2006, o M inistério da Saúde passou a denominar o PSF como Estratégia de Saúdeda Família(ESF), por meio da Portaria n 648/ 06. A alteração deu-se a fim de fortalecer a idéia da Saúde da Família como o eixo estruturante da atenção básica e não apenas como sendo mais um programa entre outros propostos pelo $\mathrm{Mi}$ nistério da Saúde 3 .

A região do Vale do Taquari (RS), na área de abrangência da 16a Coordenadoria Regional de Saúde, compreende 42 municípios e população de cerca de 350 mil habitantes. O bserva-se significativa rotatividadedemédicos eenfermeiros nas equipes de ESF, com consequentes prejuízos na implantação desta estratégia, se considerar os custos com capacitações da equi pe, interrupções nos programas de saúde, prejuízos aos usuários e, principalmente, incapacidade desses profissionais em estabelecer vínculo com a comunidade.

A ESF pretendehumanizar as práticas desaúde promovendo estreito relacionamento dos profissionais com a comunidade. Busca a integralidade da assistência e o desenvolvimento de vínculos de compromisso e de responsabilidade compartilhados entre os serviços de saúde e a população 4 . Todos devem ter jornada diária de oito horas, dedicando-se efetivamente a este trabalho, tendo condições de fazer ligação efetiva com a comunidade, conhecendo pessoalmente cada pessoa, sabendo onde mora, quem são seus parentes e qual a sua história de vida5.

Robbins ${ }^{6}$ conceitua rotatividade como a permanente saída e entrada de pessoal na organização, voluntária ou involuntariamente. Segundo 0 autor, toda organização tem alguma rotatividade, que pode ser positiva, à medida que funcionários não essenciais deixam a organização. Entretanto, a rotatividade normal mente implica perda de pessoas estratégicas, gerando fator de rupturae, consequentemente, prejudicando a eficiência organizacional.
A rotatividade de pessoal corresponde à proporção de empregados que deixam a organização. Os autores procuram associar a satisfação no trabalho com rotatividade de pessoal e acrescentam que maior satisfação está relacionada a taxas mais baixas de rotatividade. Empregados satisfeitos estão menos propensos a pensar em pedir demissão, apresentando maior probabilidade de ficarem mais tempo na organização. No entanto, concluem que empregados menos satisfeitos podem apresentar taxas mais altas de rotatividade, na medida em que sintam falta de realização profissional, recebam pouco reconhecimento no cargo, vivenciem constantes conflitos com a chefia ou colegas ou não tenham atingido patamar desejado nas suas carreiras?

A rotatividadenão écausa, mas a consequência defenômenos localizados interna ou externamente à organização. Dentre os fenômenos externos, estão a situação de oferta e procura de recursos humanos no mercado, a conjuntura econômica, as oportunidades de empregos no mercado de trabalho.

Já dentre os fenômenos internos, estão a política salarial, a política de benefícios, o tipo de supervisão, as oportunidades de crescimento profissional, o relacionamento humano dentro da organização, as condições físicas ambientais de trabalho, o moral do pessoal, a cultura organizacional, a política de recrutamento e seleção de pessoal, os critérios e programas de treinamento de recursos humanos, a política disciplinar da organização, os critérios de avaliação de desempenho e o grau de flexibilidade das políticas da organização.

Quando a perda de recursos humanos ocorre independentemente dos objetivos da organização, é preciso localizar os motivos, a fim de poder atuar sobre eles e diminuir o volume da perda ${ }^{8}$.

Acreditando que certa estabilidade na ESF é fundamental para a construção de um modelo de trabalho que contemple todos os elementos da integralidade, a rotatividade prejudica a efetividade da ESF em nossa região. Esse tipo de informação leva a buscar identificar os motivos dessa instabilidade de profissionais na ESF, tendo em vista que a qualidade da atenção à saúde tende a ser prejudicada pela falta de vinculação do profissional à determinada comunidade.

Este estudo teve por objetivo detectar e analisar as causas do índice de rotatividade dos profissionais enfermeiros e médicos das equipes da Estratégia de Saúde da Família (ESF) implantadas na região da 16a Coordenadoria Regional de 
Saúde, com no mínimo dois anos de implantação em março de 2006.

\section{Método depesquisa}

Este é um estudo do tipo exploratório e descritivo, que teve duas fases: a primeira foi quantitativa, na qual foram determinados os índices de rotatividade dos profissionais em estudo. A segunda foi qualitativa, com o objetivo de determinar e analisar as causas da rotatividade.

$\mathrm{Na}$ fase quantitativa, foram usados dados coletados nos registros do setor de recursos humanos das Secretarias M unicipais de Saúde e no Sistema deI nformações da Atenção Básica(SIAB).

Seguindo o critério do estudo, que incluía equipes com no mínimo dois anos de implantação em março de 2006, isto é, que iniciaram seu funcionamento atémarço de 2004, foram identificadas 31 equipes em 25 municípios da 16a CRS (Coordenação Regional) da ESF.

Foram encaminhados ofício e planilha para os Secretários Municipais de Saúde desses 25 municípios, solicitando dados sobre os médicos e enfermeiros que trabalharam e que ainda trabalham nas equipes de ESF.

Obtive-se retorno de vinte municípios, num total de 26 equipes. Dequatro municípios equatro equipes, foram conseguidos dados utilizando-se o SIAB.

$\mathrm{Na}$ fase qualitativa, os dados foram coletados por meio de entrevista semiestruturada, gravada e transcrita, aplicada aos profissionais em estudo, após agendamento prévio.

Os sujeitos do estudo foram sete enfermeiros esetemédicos que atuaram e/ou atuam nas equipes de ESF implantadas até março de 2004, na região da 16a CRS.

Depois de identificados os profissionais por meio das planilhas enviadas pelos municípios, foi realizada a escolha dos sujeitos por sorteio, excluindo aqueles que não preenchessem os critérios de inclusão. Para a determinação do número de sujeitos, utilizou-se o critério de saturação dos dados.

U tilizaram-se como critérios de inclusão dos profissionais estar residindo no Estado do Rio Grandedo Sul eter trabal hado em equipedeESF em município da 16a CRS no mínimo por um ano. Não foi entrevistado mais do que um sujeito da mesma categoria profissional no mesmo município.

Para a determinação dos índices de rotatividade, foi utilizada a fórmula TTT $=\mathrm{D} / \mathrm{N} \times 100^{9}$.
O cálculo dos índices de rotatividade foi realizado por ano, de 1999 até 2005. 0 cálculo foi feito por categoria profissional, isto é, médicos e enfermeiros separadamente.

As entrevistas foram analisadas com base no método de análise de conteúdo ${ }^{10}$, a partir de categorias que emergiram da análise.

Foi solicitada permissão aos Secretários Municipais de Saúde para coletar os dados no setor de recursos humanos dos municípios e também para entrevistar os profissionais das equipes de ESF.

Deacordo com o Código deÉtica em Pesquisa, previsto pelo Conselho Nacional de Saúde ${ }^{11}$, os profissionais foram previamente consultadoseinformados sobre os objetivos do estudo, assinando o termo de consentimento livre einformado.

0 projeto foi aprovado pelo comitê de ética da Universidade do Vale do Rio dos Sinos (UNISINOS).

\section{Análise de dados}

A análise quantitativa de dados revelou significativo aumento no número de equipes de saúde da família no período de 1999 a 2004. No ano de 2005, não houve aumento no número de equipes, conforme mostra o Gráfico 1.

Os resultados confirmaram a hipótese inicial de que 0 índice de rotatividade de médicos e enfermeiros é elevado, embora se apresente bastante irregular de um ano para outro. Verificou-se

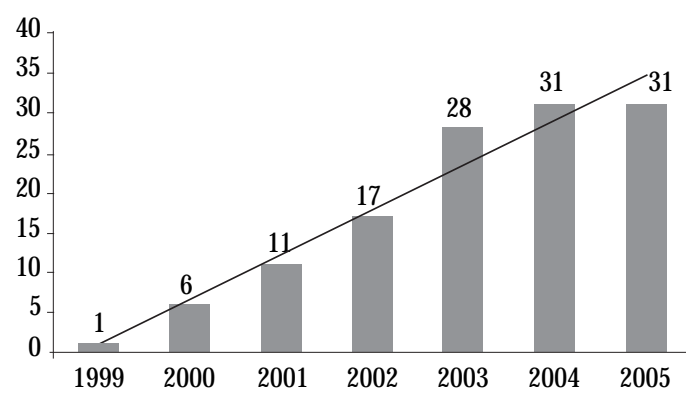

Gráfico 1. Evolução do número de equipes entre 1999 e 2005.

Fonte: Dados do Sistema del nformações da Atenção Básica(SIAB). 
que a rotatividade de médicos tem aumentado proporcionalmente ao aumento do número de equipes.

Por outro lado, é importante frisar que, nesta rotatividade, incorporou-se também um número de profissionais que optaram pela evasão do sistema, ou seja, deixaram de trabalhar com - SUS, exercendo outras atividades dirigidas à iniciativa privada. No total, foram três profissionais, sendo um enfermeiro que foi dedicar-se à docência superior e dois médicos que restringiram sua atuação ao consultório particular e ao trabalho em nível hospitalar.

A rotatividade de enfermeiros, no entanto, mostra ten dência de estabilização, que pode estar relacionada ao aumento de concursos públicos na região, conforme revela o Gráfico 2 .

Da análise de conteúdo, emergiram nove categorias: estilo de gestão; as equipes e o processo de trabalho; influência político-partidária; regimedetrabal ho e remuneração; condições detrabalho; conciliação entre a vida profissional e a pessoal; oportunidades demercado; vínculo com a comunidade; formação e perfil. Nas categorias, percebeu-se que há fatores extrínsecos e intrínsecos que influenciaram na rotatividade destes profissionais, inclusive causando alguns casos de evasão. $O$ fato é que se identificou que alguns profissionais saíram da ESF sem, no entanto, apresentar uma percepção negativa em relação à sua atuação no SUS.

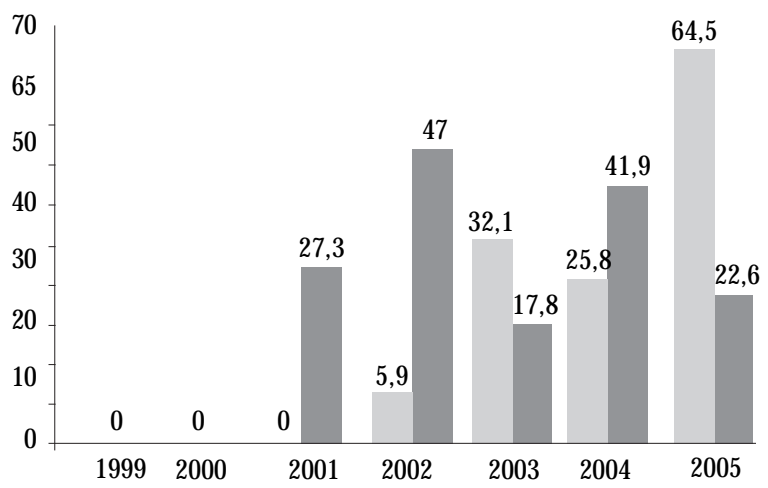

M édicos Enfermeiros

Gráfico 2. Índice de rotatividade de médicos e enfermeiros.

Fonte: Dados das Secretarias M unicipais de Saúdee do SI AB.
Estilo de gestão

Os enfermeiros percebem que o estilo de gestão autoritário e rígido, no qual as ações e projetos são impostos de cima para a base, influenciados por questões político-partidárias, podeprovocar a redução no entusiasmo, descontentamento, insatisfação, além de frustrar expectativas, sendo um dos motivos para a rotatividade. Também, as decisões centralizadas pelo gestor limitam o desenvolvimento de novas idéias, desestimulam a participação e dificultam a ocorrência da sinergia no grupo.

Nesse sentido, Dussault ${ }^{12}$ afirma que o estilo degestão autoritário não deveria ser adotado nos serviços públicos de saúde, pois não reconhece o papel central dos profissionais; portanto, sua capacidade de promover o comprometimento e envolvimento destes com os objetivos organizacionais torna-se limitada, afastando-os das atividades que não sejam eminentemente técnicas, não gerando a sinergia que ocorre quando há participação plena de todos atores envolvidos no processo.

Os entrevistados acreditam que profissionais que atuam em um ambiente mais democrático, com liberdade, são estimulados a participar dos diversos processos, sentem-se mais responsáveis e conseguem enfrentar as dificuldades no trabaIho com mais dedicação e entusiasmo.

A abertura, 0 apoio e o respaldo dado pelo gestor permitem o desenvolvimento de afinidades que podem estar relacionadas à permanência do enfermeiro na secretaria municipal da saúde ou equipe da ESF. As organizações de saúde possuem grande dependência em relação ao trabaIho de especialistas, requerendo autonomia de prática na produção dos serviços ${ }^{12}$. Já Campos $^{13}$ assevera que haveria que se inventar modos de gerenciar quenão castrassem a iniciativa dos trabalhadores nem deixassem as instituições totalmente à mercê das diversas corporações profissionais. Acrescenta que a grande questão seria a adequação entre autonomia profissional e responsabilidade dos trabalhadores.

Também, os entrevistados consideram importante o papel equilibrado do gestor, que trata as fal has como problemas de processo, não buscando encontrar culpados, mas sim as causas que possam ter gerado determinadas situações indesejadas. 0 respeito às opiniões, sem a imposição de idéias ou objetivos, são aspectos importantes para manter 0 ambiente de trabal ho agradável ea equipecoesa. As instituições devem adotar posturas flexíveis com relação às concepções 
sobre o poder e a influência, o que implica adoção de estratégias compatíveis com o envolvimento e o engajamento dos trabalhadores, possibilitando a valorização do potencial humano ${ }^{14}$.

Quanto ao estilo de gestão, os médicos da ESF entrevistados acreditam que, havendo coe rência administrativa e forma de liderança que permitam a definição clara dos papéis de cada trabalhador, bem como que sendo permitida a participação das pessoas no desenvolvimento de estratégias para alcançar os objetivos do grupo, a satisfação e o comprometimento são estimulados de modo positivo.

No quecompetia à Secretária, o relacionamento com o PSF era bom, mesmo tendo suasfalhas. Quando não era resolvido, era tratado de forma amigável. Não era imposto de cima para baixo, o queeu acho que é importante para melhorar 0 ambiente de trabalho. (M2)

Referindo-se ao papel do gestor, os entrevistados ressaltaram o preparo e a visão estratégica que este deve possuir para conduzir o grupo de profissionais ao alcance dos objetivos da ESF, atendendo as demandas da população de modo satisfatório. Também entendem que o gestor deve ter sensibilidade para equilibrar os interesses da secretaria da saúde aos interesses dos indivíduos que lá desempenham suas atividades.

0 apoio dado pela chefia e pelos gestores aos profissionais de saúde foi citado como fator que interfere no desempenho da equipe.

Campos $^{13}$ aponta a importância do comprometimento dos trabalhadores com as instituições e com os pacientes, ou seja, a implicação dos trabalhadores com a missão e os projetos institucionais. Segundo o autor, os gestores ou as chefias deveriam assumir a responsabilidade de restaurar a ligação dos trabalhadores com o trabalho no serviço de saúde, sendo necessário, ao mesmo tempo, estímulo, liberdade criadora e a delegação ampliada de responsabilidades a esses profissionais, ou seja, garantir mais coeficientes de vínculo entre profissional e paciente.

\section{Equipe e processos de trabalho}

As duas categorias profissionais em estudo consideram o trabalho em equipe fundamental para o sucesso da ESF. No entanto, observou-se que os enfermeiros percebem que esse trabalho não é desenvolvido em conjunto, mas sim isoladamente, constituindo-se mais como um trabaIho de grupo do que de equipe, isto é, não há interação entre os profissionais e unidade de objetivos. Este fato prejudica um trabalho alicerça- do na interdisciplinaridade e, na prática, reproduz-se uma atuação compartimentada com forte tendência a reproduzir o modelo médico-centrado. A insatisfação com os processos de trabal ho apareceu como uma das causas de rotatividade.

Foi relatado que as reuniões não funcionam e que cada um trabalha por si, havendo compe titividade entre a equipe: Há muitos profissionais que trabal ham aqui há muito tempo, havendo competitividade. É ruim de trabalhar nesta unidade. (E6)

Davis e N ewstrom ${ }^{7}$ procuram associar satisfação no trabalho com rotatividade de pessoal e acrescentam que maior satisfação está relacionada a taxas mais baixas de rotatividade. $\mathrm{No}$ entanto, concluem que empregados menos satisfeitos podem apresentar taxas mais altas de rotatividade, na medida em que sintam falta de realização profissional, recebam pouco reconhecimento no cargo, vivenciem constantes conflitos com a chefia ou colegas ou não tenham atingido um patamar desejado nas suas carreiras.

A equipetem queser fundamental. Tu trabalhas em PSF, em Saúde Pública, tu tens quetrabalhar em equipe, saber aceitar críticas construtivas. (E1)

Os médicos demonstraram satisfação com os processos de trabalho, entendendo-os como um trabalho em equipe. Segundo o Ministério da Saúde, o trabalho em equipe deve ser construído pela interação dos trabalhadores e usuários, estabelecendo projetos coletivos de cuidar ${ }^{15}$. Os médicos acreditam que a realização de reuniões sistemáticas entre a equipe fortalece o contato entre eles: A gente tem reunião quinzenal com toda a equipe técnica, médico, enfermeiro, agentes. (M 1)

A gestão colegiada pode ser um dispositivo desalienante para os trabalhadores, pois considera que a sua partici pação parcelar nos processos de decisão e de trabal ho produz isolamento e dificulta a realização profissional eexistencial dos profissionais de saúde ${ }^{13}$. No entanto, a efetivação deste dispositivo não ocorre de forma natural, dependendo da corresponsabilização dos envolvidos.

Os médicos relatam que nem sempre conseguem realizar as ações de promoção e prevenção como preconiza a ESF: Só que a gente não fez muito PSF lá. Nós só atendíamos, porque a de manda é de livre atendimento. (M 7)

Essa diferença de percepção entre médicos e enfermeiros provavelmente está relacionada à formação acadêmica e ao status social de cada profissão, em que se estabelece uma hierarquia médico-centrada. Os cursos de graduação ainda 
enfatizam a fragmentação do cuidado entre os trabal hadores, queentendem o trabalho em equipe como uma atividade em série, em que cada um cuida de uma parte do processo.

\section{Influência político-partidária}

$\mathrm{Na}$ pesquisa realizada, a maioria dos enfermeiros entrevistados apresentou relatos de momentos em que houve influência político-partidária em seu trabalho, com algum tipo de prejuízo na dinâmica da ESF: Aqui émuito bom trabaIhar, mas tem a questão política. Tipo a verba do PSF, a gentenão consegue usar a verba para tentar melhorar aqui. A questão do partido que dificulta o nosso trabalho. (E6)

Também entre os médicos, há relatos no mesmo sentido. Ambos destacam que, em municípios menores, é necessário muito mais “jogo de cintura" do que em maiores, pois as relações entre gestor e equipe são mais próximas.

Daí houve perseguições políticas, mesmo não tendo participado abertamente da campanha política. Resolveram cortar a complementação para induzir a minha saída, inclusive da cidade. (M 4)

Se acontece algo aqui, eles vão até o prefeito reclamar eaí o prefeito vem e diz: "Por que aconteceu isso?" (E4)

As fal as revelam a dificuldade que as equipes têm em manter um trabalho isento ante uma postura centralizadora do gestor municipal, representado pelo prefeito ou secretário de saúde. Destacam ainda que muitos agentes políticos projetam sobre a equipe da ESF expectativa de apoio eleitoral, buscando no trabal ho realizado, quetem visibilidadena população atendida, promoção pessoal, com fins político-partidários.

Percebe-se nos relatos que o vínculo empregatício precário pode ser usado como instrumento de controle político sobre a equipe da ESF, demonstrando que as causas de rotatividade são múltiplas, servindo de pretexto para exclusão ou não de membro da equipe. Um dos médicos apontou o concurso público como vantagem para a manifestação política individual, pois garante a liberdade de posicionar-se.

Tendo em vista a tradição política no país, dissociar as políticas públicas sociais da ação política partidária ainda é complexo, pois há interferências que causam prejuízos na condução dessas ações sociais, como se caracteriza a ESF.
Regime de trabalho e remuneração

Para que haja sucesso na ESF, é importante que tenhamos profissionais estáveis, para que possam conhecer a comunidadecom a qual atuarão, imergindo na sua história e organização político-social e econômica e, desta forma, maximizar estratégias de educação em saúde ${ }^{15}$.

Essa estabilidade, no entanto, ainda é algo a ser alcançado, visto que a própria legislação do SUS não prevê ferramentas de estabilidade para os profissionais da ESF, nem define parâmetros de remuneração ${ }^{16}$. A Portaria $n^{0} 1.886 / 97^{17}$, que definiu a organização do PSF, não resolveu a questão, deixando a cargo das prefeituras municipais a contratação dos profissionais, apenas recomendando o concurso público. A prática mostra, no entanto, que muitas prefeituras não realizaram concurso, gerando uma série de vínculos precários de trabalho, com grandes diferenças salariais entre municípios, o que, pela sua natureza, induz à al ta rotatividade na equipe.

$N$ as entrevistas realizadas, a maioria dos enfermeirose dos médicos evidenciou que o regime de trabal ho e a remuneração são motivos de rotatividade frequente, fazendo-os migrar de um município para outro, conforme a proposta financei ra que recebem. A questão de baixos salários e a de vínculos de trabalho precários foram relatadas pel os profissionais, revelando- os como motivos importantes de rotatividade: Foi realizado o concurso e não fui selecionado. Terminou meu contrato e não pode ser renovado. 0 salário estava adequado, pagamento em dia, a convivência com a equipe era boa no trabalho. Seriam bons motivos para permanecer. (M 2)

Percebeu-se nas falas que a estabilidade de vínculo trabalhista oficial, no caso a carteira assinada, é valorizada pelo profissional, pelas garantias que representa, favorecendo a permanência. 0 principal fator de permanência relatado foi a estabilidade proporcionada pelo concurso público: Eu gostava detrabalhar em [...]. Era mais perto de casa. A qui, eu tenho que me deslocar, mas o concurso foi o principal motivo. (E4)

Iniciei aqui em [...], quando assumi o concurso, e estou aqui até hoje, o que demonstra que a estabilidade é fator de permanência mesmo que 0 salário não seja o esperado. (E7)

A contratação por cooperativas é vista pelos profissionais como negativa, pois tolhe seus direitos trabal histas, deixando-os desassistidos em caso de demissão, doença ou gestação. Também não proporciona perspectiva de desenvolvimento profissional, uma vez que esta forma de con- 
tratação não oferece plano de carreira: E lá, como era cooperativa, pagava e atrasava o pagamento e estava meio difícil. (E4)

0 fato de ter a cooperativa aqui, sem direito a nada, é um dos fatores que desmotiva, e muito, 0 trabalho dos funcionários daqui. 0 município tem muita rotatividade de profissionais, porque, além de pagarem mal, elesnão valorizam o profissional. (E6)

Para mim, teve um motivo bem claro. Foi trazida uma cooperativa para cá e os profissionais que eram contratados por CLT, com todos os direitos trabalhistas, foram demitidos, e teriam de se associar a esta cooperativa e passar a trabalhar como autônomo ea receber via cooperativa. (M 5)

\section{Condições de trabalho}

A falta de estrutura e condições de trabalho foi relatada de várias maneiras, como a falta de telefone, pessoal, carro, espaço físico e estrutura do local, constituindo-se fator de insatisfação no trabalho. 0 difícil acesso ao local de trabal ho também surgiu como causa de rotatividade: O PSF não tinha telefone, acesso para deficientefísico. Falta de pessoal aqui no posto. Já há três semanas agendo uma visita com o ACS e não consigo sair. (E5)

A existência de referências para encaminhamento dos usuários e a resolutividade desta são grande preocupação das equipes, sendo apontada como fator de segurança para os profissionais, favorecendo a permanência no município: A gente tem à disposição 0 acesso, 0 que facilita nosso trabalho e o encaminhamento de pacientese o tratamento. (M 3)

\section{Conciliação entre a vida profissional e a pessoal}

0 fato de conseguir conciliar a vida profissional com os interesses pessoais é um importante fator de permanência e evasão eventual dos trabal hadores nos municípios, na medida que perspectivas profissionais e pessoais são alcançadas ou não. Isso aparece em vários relatos: Poder retornar à terra natal e desta forma estar novamente junto à família. (M 5)

Não tive problemas de adaptação. Já conhecia a cidade. M eus pais, minha mãe moram em [...]. Por enquanto, eu fico, mesmo que o salário não seja bom. (M 4)

Estabelecer um relacionamento familiar no local também foi relatado como fator de permanência: N esse meio tempo eu casei aqui, ejá tenho dois filhos pequenos. Já tenho o vínculo com o local. (M 1)
Porqueo meu namorado se estabeleceu aqui. A gente mora junto. (E6)

A distância da cidade onde mora a família também é decisiva: A distância muito grande, então fica difícil de voltar, eisso eu coloquei antes na decisão entre os municípios. (M 3)

A questão econômica tem peso na decisão: 0 custo de vida é mais barato. Eu não pago aluguel. (E6)

Oportunidades de mercado

0 mercado de trabalho, para os médicos, é amplo, principalmente em municípios do interior do estado. Essa constatação ficou clara nas entrevistas realizadas, em que as falas revelaram grande oferta de oportunidades, favorecendo a possibilidade de obter nível social mais alto, com rendimentos melhores, por meio do desempenho profissional em mais de uma atividade. Na prática, percebeu-sequeo profissional vinculado à ESF tem outras atividades, embora tenha que cumprir quarenta horas semanais de trabalho, conforme prevê a regulamentação da ESF. Os profissionais afirmaram exercer atividades complementares em consultórios ou plantões noturnos, mas tendem a se manter ativos na ESF devido à estabilidadeque proporciona: $\mathrm{N}$ a medicina do trabalho, tu tem um pilar, uma garantia, o meu ganha-pão. O sdemaiseu adiciono para conseguir um algo mais. Tu podeagregar um ao outro. Todo mundo tem que trabalhar um pouco mais. (M 1)

Uma das causas que pode influenciar a rotatividadeéo mercado de trabalho, relacionado ao emprego e desemprego e à composição da força de trabalho'.

As falas revelaram queo excesso de trabalho, além de mais rendimentos, também traz associada carga de estresse, havendo consciência dos prejuízos inerentes à saúde do trabalhador e à qualidade do trabalho: 0 plantão no hospital é muito estressante, e aí a hora tem que ser mais bem remunerada. I sso cansa com o tempo. Fiz isso no início da carreira, por necessidade até de aumentar os ganhos. Só que com o tempo isso vai cansando. Fazendo doze horas por dia é cansativo. Então cheguei à conclusão de quequalidadedevida tem um preço. E se tem que cuidar da saúde, tenho que cuidar da minha primeiro. (M 7)

Muitos médicos vêm para a região com 0 propósito de adquirir prática de trabalho temporário, muitas vezes por não terem conseguido passar para a residência médica, ou para conseguir abrir o seu próprio consultório. Outros deixam o trabalho com a ESF para realizar especia- 
lização e assim poder montar o seu consultório, abandonando a ESF devido à jornada de trabaIho: Por causa da minha especialização em dermatologia e cirurgia e medicina estética. E aí eu fiquei sabendo que não tinha nenhum profissional em [...], era um município próximo. Tinha amigosaqui. Então eu memudei para cá. Tive a oportunidade de trabalhar no posto também. Então eu conciliei. (M 6)

A alta demanda por profissionais tem levado a uma competição entre osmunicípios, com ofertas salariais que têm aumentado a rotatividade de médicos: Há um mercado muito aberto, com muitas vagas, o que possibilita aos profissionais amplas possibilidades de escolha. Existe também na nossa regi onal uma espécie de competição pre datória: quando um município aumenta o salário do médico, o outro tem que aumentar também, ou isso gera rotatividade de profissionais. (M 4)

Esse fato não se repete entre os enfermeiros, para os quais as ofertas são mais escassas, o que tem se refletido numa tendência à maior estabilidade do quadro, principalmente a partir da realização de concursos públicos. A grande maioria dos enfermeiros da ESF exerce seu trabalho em apenas um local.

\section{Vínculo com a comunidade}

A noção de vínculo faz refletir sobre a responsabilidade e o compromisso dos profissionais de saúde com os usuários dos serviços. Criar vínculos implica ter relações tão próximas e tão claras que nos sensi bilizamos com todo o sofrimento daquele outro, sentindo-se responsável pela vida e morte do paciente, possibilitando uma intervenção nem burocrática nem impessoal ${ }^{18}$.

Observa-se que, por parte de alguns profissionais enfermei ros que atuam nas equipes da ESF da região, esses vínculos estão presentes e tornam o trabalho mais significativo: $\mathrm{Na}$ comunidade, tu indo até lá acaba criando vínculo com os pacientes e eles confiam em ti. N esse sentido, édiferente de uma UBS, que tu vem fazer um curativo, consultar. $\mathrm{Na}$ ESF édiferente, tu consegue criar o vínculo. Claro que até tu conhecer a tua comunidade leva um tempo. (E4)

Um dos conceitos de acolhimento é a relação humanizada, acolhedora, que os trabalhadores e os serviços devem estabelecer com todos os tipos de usuários ${ }^{18}$.

0 relato de um dos enfermeiros reforça que muitos deles estabelecem vínculos afetivos e de responsabilização com os usuários: Eu não me vejo fora daqui. Eu amo as pessoas daqui. Eu co- nheço todas as pessoas. A companhei de pequeno. Conheço cada um, quando se casaram, ficaram gestantes. $E$, quando nasceram os bebês, acompanhei na puericultura. Sei o nome deles, o nome do namorado. Quando brigam, vêm aqui pedir conseIho. (E3)

Teve um período de adaptação normal. Colonização alemã. Eu não sei falar alemão. Aquelas coisas, costume diferente. Eu já vim disposto a me integrar à comunidade e partici par das atividades, festas, jogar no ginásio, conversar com todo mundo, aquelas coisas queem pouco tempo foram quebrando a resistência da população. E aí eu já me senti integrante da comunidade. (M 1)

Essa experiência, no entanto, não é regra ge ral, ou seja, também há profissionais que não se relacionam com os usuários e com o serviço de forma comprometida. A fala a seguir exemplifica essa diferença nas relações com o usuário, nas equipes de ESF: Eu vejo as pessoas num descaso total. Eles não se preocupam seum desmaia. Aquele ali está sempre desmaiando; eu já conheço. Eles criam rótulo. (E2)

Constatou-se também que nem todos os profissionais conseguem estabelecer vínculos significativos com a comunidade, o que contribui para 0 aumento da rotatividade dos enfermeiros. A fala a seguir é um exemplo dessa situação: Não tinha muito vínculo. Não conhecia a cidade. Só conhecia minha colega. E, no final de semana, tu não queres ficar na cidade. (E4)

Sobre a ausência de vínculo, Campos $^{19}$ afirma que a alienação dos profissionais de saúde em relação a seu trabal ho contribui para a redução do grau de responsabilização e da criação de vínculos entre profissionais eusuários. Além disso, estimula a separação e a falta de integração entre os membros da equipe.

Essa questão afeta tanto os enfermeiros quanto os médicos que atuam nas equipes da ESF. Os relatos das experiências desses últimos apontam para essa afirmação, ou seja, os médicos também destacam a importância de formar vínculos com a comunidade como fator importante para permanecer nas equipes. Referem quegradativamente vão aumentando as relações de comprometimento com a comunidade, conformerevelam em seus depoimentos: Tu ver o paci ente num consultório é uma coisa. Quando tu vaisa casa deles, ébem diferente. Tem um vínculo muito melhor, porque eles estão no local deles, e aí eles se abrem e tu podes observar o jeito que eles vivem. 0 vínculo dos dois lados: às vezes, el echega com uma queixa esomente no final da consulta é que verdadeiramente tu descobres o que esse paciente precisa. (M 6) 
Eu achei a receptividade muito boa e aos poucos foram adquirindo confiança no tratamento. Às vezes, são coi sas pequenas que a gente faz e não se tem o resultado imediato, mas a população se sente segura e se sente bem atendida quando fazemos a visita ededicamos um pouco de tempo para a avaliação da família. (M 3)

Pode-se pensar no vínculo em três dimensões: como afetividade, como relação terapêutica e como continuidade ${ }^{20}$.

Referindo-se a vínculos com a comunidade, um médico relatou sua experiência, a qual teve reflexos na sua formação profissional e pessoal: Eu me envolvia muito com os problemas daquela população. Não tem como tu conseguir trabalhar aquelas "horinhas" e esquecer tudo aquilo lá. Isso fica muito dentro da gente. E isso éuma lição para a vida toda, seja profissional ou pessoal. A gentese envolve com essas pessoas. A gente se dá conta dessas dificuldades. (M 5)

\section{Formação e perfil}

A formação em saúde como uma das categorias que pode interferir nos índices de rotatividade dos profissionais que integram as equipes de saúde da família é também nosso objeto de análise neste estudo. Vários autores ${ }^{18,21,22}$ apontam que a formação dos profissionais de saúde tem permanecido al heia à organização da gestão setorial e ao debate sobre a estruturação do cuidado.

Essa questão é confirmada pelos relatos dos profissionais, apontando para as falhas na formação que vem interferindo na estruturação das equipes e na organização dos processos de trabalho: Eu senti falta de perfil, porque temos colegas que estão há trinta anos trabalhando e têm muita dificuldade. Eles não conseguem incorporar essa proposta. Tem outros profissionais chegando que já entendem melhor a proposta. Eu acho até por causa da faculdade, que émais recente. (E7)

Quando se perdeu esse rumo, foi se fragmentando a saúde; a medicina ficou toda especializada e foi se direcionando para essas especialidades. A própria enfermagem hojeétoda fragmentada. Então aquela atenção à saúde básica, para que não se adoeça, começou a se resgatar com a ESF. (E2)

A fragmentação da formação e o crescimento das especialidades são apontados também como fatores que dificultam a integração dos profissionais nas equipes e na relação com os usuários. N essesentido, Ceccim eCarvalho ${ }^{23}$ afirmam que o crescimento das especializações não garante a satisfação da população no que concerne ao atendimento, aos serviços e à própria relação com os profissionais de saúde. E um dos fatores predisponentes a esta postura éjustamente a fragilidade do ensino sobre o SU S na formação básica e a ausência dos termos da integralidade como critério para estipular as práticas.

A formação dos médicos também denota fragilidades, principalmente em relação ao processo de sistematização, organização e implementação do SUS: M asum pouco também pelo meu perfil que é de atender, atender. 0 significado realmente de trabalhar a prevenção está distorcido. (M 3)

M erhy e Franco ${ }^{24}$, preocupados com a ética do acolhimento e da responsabilidade, alertam que a proposição da ESF pode conter apenas uma intenção racionalizadora, incluindo a idéia geral de "focalização", não bastando adotar o princípio da adscrição de clientela, senão repensarmos a forma de produção de cuidados em saúde. Pouco adiantará produzir atos de saúde sem a concreta responsabilização por parte dos serviços de saúde, sem garantir um sistema de saúde resolutivo e acolhedor, sem substituir a lógica procedimento-centrada ou medicocêntrica pela escuta às necessidades sociais de saúde dos usuários.

\section{Consideraçõesfinais}

A rotatividade de médicos e enfermeiros que atuam naEstratégia deSaúde da Família podeser considerada alta, conforme apontam as informações coletadas na pesquisa. 0 índice que foi apurado mostra-se irregular de um ano para o outro, mas percebe-se tendência de aumento da rotatividade entre os médicos, à medida que são implantadas mais equipes da ESF. Já quanto aos enfermeiros, há certa estabilidade, que pode ser relacionada à realização de concursos públicos na região.

As entrevistas realizadas apontaram como causas principais da rotatividade uma série de aspectos, analisados anteriormente, o que demonstra a realidade complexa do trabalho das equipes desaúde da família. M édicos e enfermeiros, nesse contexto, são desafiados a exercerem papel sociopolítico, movendo-se entre diversos interesses em conflito.

A rotatividade de enfermeiros e médicos é condicionada por motivos tanto objetivos quanto subjetivos. Em outras palavras, a motivação oscila desde motivos concretos, como o vínculo precário na contratação, dificuldades de relacionamento político entre profissional e gestor, até questões como a realização profissional nas atividades desenvolvidas no âmbito dessa política. 
Diante desses resultados, considera-se que há a necessidadedepromover a desprecarização dos vínculos trabalhistas, principalmente por meio de concurso público e de um plano de cargos e salários que estimule os profissionais à qualificação para o trabal ho na ESF ea permanecer nas equipes. 0 estilo degestão que favorece a permanência dos profissionais é o participativo, que pode resultar em satisfação e comprometimento com a proposta da ESF. As informaç̧ões também indicam a necessidade de primar-se por uma formação profissional qualificada. Percebeu-se 0 imperativo de criar espaços que promovam a educação permanente em saúde, visando diminuir o impacto da formação fragmentada centrada no modelo biomédico e a desencadear mudanças curriculares que possibilitem maior interação entre as instituiç̃ões formadoras, serviços e comunidade, buscando a implementação da integralidade nas práticas de saúde.

A ESF, enquanto proposta de reordenação das práticas de saúde nas comunidades, tem alcançado resultados expressivos em muitos municípios. Ao mesmo tempo, apresenta problemas relevantes, entreos quais a rotatividadeécentral. N este estudo, levantaram-se al gumas das causas desse problema, a partir da fala dos enfermeiros e médicos. Constatou-se que a rotatividade éaltamente prejudicial para a efetividade dos resultados esperados. No entanto, resolver esse problema constitui-se um grande desafio, tendo em vista a multiplicidade das causas.

\section{Colaboradores}

CRG M edeiros, AGW Junqueira, G Schwingel, I Carreno, LAP Jungles e OM FL Saldanha participaram igualmente de todas as etapas da elaboração do artigo. 


\section{Referências}

1. Brasil. M inistério da Saúde. Secretaria de Assistência à Saúde. Saúde da Família: uma estratégia de organização dos serviços de saúde. Brasília: M inistério da Saúde; 1996.

2. Franco TB, M erhy EE. PSF: contradições de um programa destinado à mudança do modelo tecnoassistencial. Campinas; 1999. [M imeo]

3. Brasil. Portaria $n^{\circ} 648$ de 28 de março de 2006, que aprova a Política Nacional de Atenção Básica, estabelecendo a revisão de diretrizes e normas para a organização da Atenção Básica para o Programa Saúde da Família (PSF) e o Programa Agentes Comunitários de Saúde (PACS). Diário O ficial da União 2006; 28 mar.

4. Sousa MF. A enfermagem reconstruindo sua prática: mais que uma conquista no PSF. Rev. bras. enferm. 2000; 53(2):25-30.

5. Brasil. M inistério da Saúde. Departamento de Atenção Básica. Guia prático do Programa Saúde da Família. Brasília: Ministério da Saúde; 2001.

6. Robbins SP. Comportamento organizacional. 9a ed. São Paulo: Prentice Hall; 2002.

7. Davis K, Newstrom JW. Comportamento humano no trabalho: uma abordagem psicológica. São Paulo: Pioneira Thomson Learning; 2001.

8. Chiavenato I. Recursos humanos. 6a ed. São Paulo: Atlas; 2000.

9. Mobley WH. Turnover: causas, consequências e controle. Porto Alegre: Ortiz; 1992.

10. Bardin L. Análise de conteúdo. 3ạ ed. Lisboa: Edições 70; 2004.

11. Brasil. Resolução n 196 de 16 de outubro de 1996. A prova a Diretrizes e normas regulamentadoras de pesquisas em seres humanos. Diário O ficial da U nião 1996; 16 out.

12. Dussault G. A gestão dos Serviços Públicos de Saúde: Características e exigências. Rev. Adm. Pública 1992; 26:2-19.

13. Campos GWS. Subjetividade e administração de pessoal: considerações sobre o modo de gerenciar 0 trabalho em equipes de saúde. In. M erhy $E$, Onocko $R$, organizadores. Agir em saúde: um desafio para o público. 2a ed. São Paulo: Hucitec; 2002.

14. Kanaane R. Comportamento humano nas organizações: o homem rumo ao século XXI. São Paulo: Atlas; 1999.
15. Brasil. Ministério da Saúde. Secretaria de Gestão do Trabalho e da Educação na Saúde. Curso de formação de facilitadores de educação permanente em saúde: unidade de aprendizagem - trabalho e relações na produção do cuidado em saúde/ Brasil. Rio de Janeiro: M inistério da Saúde/Fiocruz; 2005.

16. Bomberger SMT. A Estratégia de Saúde da Família numa perspectiva ambiental para a promoção de saúde. Boletim Saúde 2003; 17(2):15-24.

17. Brasil. Portaria n 1.886 de 18 de dezembro de 1997. A prova as Normas e Diretrizes do Programa de Agentes Comunitários de Saúde e do Programa de Saúde da Família. Diário O ficial da União 1997; 18 dez.

18. Merhy EE. Em busca do tempo perdido: a micropolítica do trabalho vivo em saúde. In: M erhy EE, Onocko R, organizadores. Agir em saúde: um desafio para o público. São Paulo: Hucitec; 1997. p. 71-112.

19. Campos GWS. A Saúde Pública e a Defesa da Vida. São Paulo: Hucitec; 1994.

20. Junior AGS, M ascarenhas MTM . Avaliação da Atenção Básica em Saúde sob a ótica da Integralidade: Aspectos Conceituais e M etodológicos. In: Pinheiro R, M attos RA, organizadores. Cuidado: as fronteiras da integralidade. São Paulo: Hucitec; Rio de Janeiro: Abrasco; 2004.

21. Ceccim R, Feuerwerker LCM . O Quadrilátero da Formação para a área da Saúde: Ensino, Gestão, Atenção e Controle Social. Physis (Rio J.) 2004; 14(1):41-65.

22. Campos GWS. Paidéia e modelo de atenção à saúde: um ensaio sobre a reformulação do modo de produzir saúde. Olho mágico 2003; 10(2):7-14.

23. Ceccim RB, Pinheiro R, Mattos RA. Ensinar saúde: a integralidade e o SUS nos cursos de graduação na área da saúde. Rio de Janeiro: CEPESC/Abrasco; 2006.

24. M erhy EE, Franco TB. Programa de Saúde da Família: somos a favor ou contra? Saúde em Debate 2003; 26:118-122.

Artigo apresentado em 31/07/2007

Aprovado em 15/10/2007

Versão final apresentada em 10/09/2008 